\title{
ANALISIS FLIGHT DATA RECORDER KECELAKAAN PESAWAT TERBANG A320 UNTUK MENDAPATKAN STALL SPEED DAN PROSES REKONSTRUKSI KECELAKAAN MENGGUNAKAN SOFTWARE FLIGHTSCAPE
}

\author{
Mohammad Ardi Cahyono ${ }^{1}$, Andry Renaldy Pandie ${ }^{2}$ \\ Teknik Penerbangan \\ Sekolah Tinggi Teknologi Adisutjipto \\ Jl. Janti Blok-R Lanud Adisutjipto Yogyakarta \\ mactos774@gmail.com andrev.renaldv@gmail.com
}

\begin{abstract}
Aircraft is transportation mode which in it operation refer to all operation procedure be valid. Although that, accident probability will be occur. To help human/analysts to find out and learn more about aircraft accident causes then black box installed in aircraft. Parameters which recorded by black box still in bynari data type, so it must to be processing using Flightscape software and Google Earth application in order to represented and understood by analysts to help analysis process. It so happens, main purposes from this research are to know stall speed value from aircraft A320 which analyzed. Methods which used to finished this research that is simulation method in Flightscape to get video/animation of flight accident reconstruction, and analysis method as manually to get stall speed of aircraft.Based on analysis result, be obtained that aircraft stall speed value is 348,0942 kts (when first stall warning) and 150,8151 kts (when three secons before crash).
\end{abstract}

Keywords : FDR, stall, reconstruction, flightscape, google earth

\begin{abstract}
ABSTRAK
Pesawat terbang merupakan moda transportasi yang dalam pengoperasiannya merujuk pada semua prosedur pengoperasian yang berlaku. Walaupun demikian, tetap saja kemungkinan kecelakaan ada. Demi menunjang dan membantu manusia dalam mengetahui dan mempelajari penyebab kecelakaan pesawat terbang maka dipasanglah black box di pesawat terbang. Parameter-parameter yang terekam oleh black box masih dalam bentuk binary data sehingga perlu diolah menggunakan software Flightscape dan aplikasi Google Earth agar dapat direpresentasikan dan dipahami untuk membantu proses analisis. Adapun tujuan utama dari penelitian ini yaitu untuk mengetahui nilai kecepatan stall yang dialami oleh pesawat terbang A320 yang dianalisis. Metode yang digunakan yaitu metode simulasi di Flightscape untuk medapatkan video/animasi rekonstruksi kecelakaan penerbangan, dan metode analisis secara manual untuk mendapatkan kecepatan stall pesawat. Berdasarkan hasil analisis maka nilai kecepatan stall yang dialami oleh pesawat adalah 348,0942 kts (saat stall warning pertama) dan 150,8151 kts (saat tiga detik sebelum crash).
\end{abstract}

Kata kunci : FDR, stall, rekonstruksi, flightscape, google earth 


\subsection{Pengantar}

\subsubsection{Pendahuluan}

Petunjuk-petunjuk untuk mendapatkan informasi penyebab kecelakaan pesawat terbang selama ini dapat diakses dari "black box" (flight data recorder/FDR dan cockpit voice recorder/CVR) yang terpasang pada pesawat terbang. Kecelakaan-kecelakaan itu salah satunya terjadi karena adanya penurunan/perubahan prestasi terbang dari pesawat dan perubahansikap (defleksi bidang-bidang kendali) dari pesawat yang berpengaruh terhadap kestabilan pesawat sehingga pesawat sulit dikendalikan. Namun, parameter/data-data yang terekam itu masih dalam bentuk binary data sehingga perlu diolah agar didapatkan data yang dapat direpresentasikan dan dipahami untuk membantu proses analisis. Pengolahan data-data yang terekam itu membutuhkan software seperti Flightscape.

\subsubsection{Tinjauan Pustaka}

Dalam menyelesaikan penelitian ini, sebagai bahan kajian pustaka maka digunakan rujukan tulisan seperti :

1. Dalam skripsi Purwa Adiyasa (11050111), Sekolah Tinggi Teknologi Adisutjipto Yogyakarta yang berjudul Pemodelan Pesawat CN-235 dengan Software Simulasi X-Plane 10 menjabarkan tentang pemodelan pesawat di software X-Plane 10 kemudian dilakukan simulasi terhadap prestasi terbang pesawat tersebut, yang terdiri atas simulasi takeoff stall, balance field length, dan absolute ceiling. Dari hasil penelitiannya, didapatkan bahwa ratarata stall speed pesawat $10 \mathrm{knot}$, fase takeoff dengan konfigurasi flap 15 dan kondisi MTOW didapat lift off dengan jarak $778 \mathrm{~m}$ dan mencapai ketinggian 35 feet dengan jarak $936 \mathrm{~m}$, balance field length nilai V1 diperoleh $157,5 \mathrm{ft} / \mathrm{s}$, hasil absolute ceiling mencapai ketinggian 32.880 feet, dandampak dari airfoil yang berbeda sangat berpengaruh terhadap performa pesawat.

Perbedaan antara penelitian yang dilakukan oleh Purwa Adiyasa dan tulisan dalam penelitian ini adalah terletak pada :

a. Pada penelitian ini ( Analisis Flight Data Recorder Kecelakaan Pesawat Terbang A320 untuk Mendapatkan Stall Speed dan Proses Rekonstruksi Kecelakaan Menggunakan Software Flightscape) dilakukan proses pengunduhan yang selanjutnya data-data yang diperoleh dari FDR dan data pesawat A320 untuk proses analisis.

b. Pada skripsipenelitian ini dilakukan proses analisis secara manual kecepatan stall/stall speed pesawat yang mengalami kecelakaan penerbangan, kemudian dibandingkan dengan kecepatan yang terekam di FDR.

c. Pada penelitian ini dilakukan proses rekonstruksi kecelakaan penerbangan (menggunakan software Flightscape) sedangkan Purwa Adiyasa melakukan simulasi terbang (menggunakan software X-Plane 10).

2. Dalam skripsi Akbar Asyisyam (13601046), Institut Teknologi Bandung yang berjudul Analisis Prestasi Terbang Boeing 747-400 Menggunakan Software X-Plane Pada Fasa Takeoff dan Climb menjabarkan tentang proses rekonstruksi dan simulasi terbang pada fasa takeoff dan climb menggunakan X-Plane yang beberapa parameter inputan awal berasal dari FDR, yang bertujuan untuk menganalisis hasil yang diperoleh dari FDR dan hasil dari X- 
Plane. Titik berat dari penelitiannya adalah untuk mengetahui seberapa optimal seorang pilot untuk menerbangkan suatu pesawat, selain itu juga untuk mengetahui keakuratan X-Plane. Dari penelitiannya didapatkan bahwa hasil simulasi yang dikeluarkan oleh X-Plane tidak sama persis walaupun inputan yang diberikan sama dengan data-data yang berada FDR; pada fasa lepas landas untuk parameter berat (tidak terlalu berbeda), parameter ketinggian (penyimpangan antara FDR dan simulasi X-Plane sebesar 8,91\%), parameter airspeed $(12,3 \%)$, parameter angle of attack (pergerakan sudut yang dihasilkan oleh X-Plane lebih cepat naik dibandingkan dengan FDR); pada fasa terbang menanjak untuk parameter berat (tidak terlalu berbeda), parameter ketinggian (penyimpangan antara FDR dan simulasi XPlane sebesar 1,45\%), parameter airspeed (8,7\%), parameter angle of attack (konstan pada interval tertentu).

Perbedaan antara penelitian yang dilakukan oleh Akbar Asyisyam dan tulisan dalam penelitian ini adalah terletak pada:

a. Tipe pesawat yang dianalisis, Akbar (B737-400) sedangkan di penelitian ini (A320200)

b. Software simulasi dan rekonstruksi yang digunakan, Akbar (X-Plane) sedangkan di penelitian ini (Flightscape)

c. Fasa terbang yang dianalisis, Akbar (fasa lepas landas dan fasa terbang menanjak yang nantinya dilihat perbedaan antara hasil yang ditampilkan oleh X-Plane dan FDR) sedangkan di penelitian ini (proses pengunduhan data dari FDR, proses rekonstruksi dan simulasi penerbangan, dan kecepatan stall ketika pesawat dalam fasa steady flight/cruising).

3. Dalam tesis Javensius Sembiring (23605004), Institut Teknologi Bandung yang berjudul Rancang Bangun Sistem Rekonstruksi Lintas Terbang Pesawat Udara dengan Perangkat Lunak X-Plane menjabarkan tentang proses melakukan rekonstruksi lintas terbang untuk memprediksi dan mengetahui lintas terbang dan posisi terakhir pesawat mengalami hilang kontak yang mana data dari black box belum ditemukan. Untuk melakukan penelitiannya, proses rekonstruksi dibagi menjadi 3 tipe sistem rekonstruksi yaitu tipe A (mampu merekonstruksi kembali karakteristik terbang pesawat udara berdasarkan data yang di-inputkan pada sistem, parameter minimal yang digunakan adalah 12 parameter, hasil rekonstruksinya lengkap), tipe B (merancang kembali sistem kendali untuk mengarahkan pergerakan pesawat udara berdasarkan waypoint tertentu, semakin banyak waypoint yang digunakan maka hasil rekonstruksi akan mendekati flight path objective, hasil rekonstruksinya cukup lengkap), dan tipe $\mathrm{C}$ (membutuhkan banyak skenario untuk memprediksi lintas terbang yang terjadi, hasil rekonstruksinya kurang lengkap). Dari hasil penelitiannya disimpulkan bahwa sistem rekonstruksi lintas terbang yang dirancang dapat digunakan untuk memprediksi karakteristik terbang pesawat udara baik dengan data yang lengkap maupun data yang sangat minim.

\section{Latar Belakang Masalah}

Pesawat terbang merupakan salah satu moda transportasi yang boleh dikatakan aman dan nyaman bila dibandingkan dengan moda transportasi yang lain. Hal ini karena dalam pengoperasiannya merujuk pada semua prosedur pengoperasian yang berlaku seperti persiapan dan perencanaan penerbangan, membutuhkan komunikasi yang intens antara flight crew dengan petugas ATC (Air Traffic Controller),prosedur maintenance, dan prosedur 
menerbangkan pesawat. Walaupun sudah banyak kegiatan yang dilakukan untuk meminimalisir kecelakaan, namun tetap saja kemungkinan kecelakaan ada. Karena teknologi manusia belum dapat menghilangkan risiko kecelakaan secara total, maka manusia masih berusaha untuk mempelajari setiap penyebab kecelakaan yang terjadi sehingga ke depannya dapat tercipta suatu teknologi yang optimal untuk mencegah terjadinya kecelakaan dengan penyebab yang sama.

Demi menunjang dan membantu manusia dalam mengetahui dan mempelajari penyebab kecelakaan pesawat terbang, maka dipikirkanlah sebuah cara yang mampu memberikan petunjuk yang dimaksud. Petunjuk untuk mendapatkan informasi penyebab kecelakaan pesawat terbang selama ini dapat diperoleh dari perubahan sikap dan posisi pesawat terbang, serta juga percakapan-percakapan yang terjadi selama penerbangan menjelang kecelakaan. Petunjuk-petunjuk yang dimaksud dapat diakses dari "black box" (flight data recorder/FDRdan cockpit voice recorder/CVR) yang terpasang pada pesawat terbang.

Sampai saat ini sudah terjadi banyak kecelakaan pesawat terbang. Kecelakaan-kecelakaan itu salah satunya terjadi karena adanya penurunan/perubahan prestasi terbang dari pesawat (kemampuan untuk steady, dan lain-lain) dan perubahansikap (defleksi bidang-bidang kendali) dari pesawat yang berpengaruh terhadap kestabilan pesawat sehingga pesawat sulit dikendalikan. Namun, parameter/data-data yang terekam itu (berkaitan dengan prestasi terbang dan sikap pesawat) yang terekam tersebut masih dalam bentuk binary data sehingga perlu diolah agar didapatkan data yang dapat direpresentasikan dan dipahami untuk membantu proses analisis. Pengolahan data-data yang terekam itu membutuhkan software seperti Flightscape.

Pemodelan dan rekonstruksi kecelakaan yang dilakukan digunakan untuk mengetahui penyebab kecelakaan pesawat. Stall sendiri merupakan kondisi dimana pesawat kehilangan lift sehingga pesawat tidak sanggup lagi melayang di udara yang kemudian jatuh dari ketinggian tanpa terkendali yang disebabkan oleh angle of attack $(\alpha)$ yang makin membesar dan melampaui $\alpha$ kritis (tergantung pada bentuk airfoil).

\section{Metodologi Penelitian}

Metode yang digunakan dalam menyelesaikan penelitian ini yaitu metode simulasi di Flightscape (Insight Analysis dan Insight Animation) untuk medapatkan video/animasi rekonstruksi kecelakaan penerbangan, dan metode analisis secara manual untuk mendapatkan kecepatan stall pesawat. Sebagai alat bantu hitung dalam analisis manual maka digunakan program Matlab. Selanjutnya untuk mendapatkan jalur terbang/flight path maka menggunakan aplikasi google earth.

\subsection{Prinsip Kerja Sistem}

Stall merupakan suatu kondisi dimana pesawat kehilangan lift sehingga pesawat tidak sanggup melayang di udara yang kemudian jatuh dari ketinggian tanpa terkendali yang disebabkan oleh angle of attack $(\alpha)$ yang makin membesar dan melampaui $\alpha$ kritis (tergantung pada bentuk airfoil) atau melampaui $\mathrm{C}_{\mathrm{L} \max }$ yang dimiliki oleh airfoil. 
Kecepatan stall merupakan kondisi dimana airspeed pesawat terbang telah mencapai $\mathrm{C}_{\mathrm{L} \max }$, karena stall pada wing dimulai dari titik ini. Bila $\mathrm{V}_{\text {pesawat }}<\mathrm{V}_{\text {stall }}$ atau $\alpha>\alpha_{\max }$ maka pesawat akan mengalami stall (kehilangan lift). Kecepatan stall akan makin bertambah bila permukaan wing terkontaminasi dengan material-material yang membuat permukaannya menjadi kasar (contohnya es yang menumpuk pada wing surface).

Dalam penelitian ini, kondisi terbang dari pesawat diasumsikan berada dalam kondisi steady level, danaliran udara dianggap compressible flow (karena kerapatan fluida fluktuatif pada tiap ketinggian) sehingga persamaan-persamaannya dijabarkan seperti di bawah ini.

Bilangan Oswald dari suatu pesawat terbang dapat juga dihitung berdasarkan persamaan:

$$
e \approx 461 \times\left(-\left(0,045 \times A R^{0,68}\right) \times\left(\cos \Lambda_{0,25 \text { chord }}\right)^{0,15} 3,1\right.
$$

Untuk mendapatkan jarak (range) yang sudah ditempuh oleh pesawat ketika take-off sampai kondisi tetentu maka digunakanlah pendekatan rhumb line, yang mana pada pendekatan ini dihitung selisih latituda antara latituda take-off dengan latituda kondisi tertentu yang dijabarkan dalam persamaan (3.2).

$R=$ Latitude $\times 60 \mathrm{NM}$

Kecepatan suara yang dialami oleh suatu pesawat terbang berdasarkan ketinggian terbangnya dirumuskan dengan persamaan (3.3) berikut:

$V_{a}=\sqrt{\gamma \times R_{\text {ideal }} \times T_{\text {alt }}}$

Dari persamaan calibrated airspeed (persamaan 3.4) berikut selanjutnya diturunkan untuk mendapatkan nilai tekanan total $\left(\mathrm{P}_{0}\right)$ karena data yang terekam di FDR adalah data CAS.

$V_{C A S}^{2}=\frac{2 \times V_{\alpha}^{2}}{\gamma-1} \times\left\{\left(\frac{P_{0}-P_{1}}{P_{s}}\right)^{\gamma-1 / \gamma}-1\right\}$

Kecepatan Mach dari suatu pesawat terbang didefinisikan sebagai perbandingan antara kecepatan relatif terbang suatu pesawat terbang terhadap kecepatan suara di sekitarnya, yang dirumuskan dengan:

$M=\frac{V_{T A S}}{V_{\alpha}}$ atau $M^{2}=\frac{2}{\gamma-1}\left\{\left(\frac{P_{0}-P_{1}}{P_{1}}+1\right)^{\frac{\gamma-1}{\gamma}}-1\right\}$

Dari hubungan antara $\mathrm{M}, \mathrm{V}_{\mathrm{TAS}}$, dan $\mathrm{V}_{\mathrm{a}}$ maka persamaan (3.6) menjadi:

$V_{T A S}=M \times V_{a}$

Untuk mendapatkan berat pesawat saat mengalami kondisi tertentu yang telah ditentukan (misalnya saat stall warning pertama kali terdengar,dan lain-lain) maka digunakan persamaan mission fuel fraction yang dikutip dari buku Jan D. Roskam yang berjudul Airplane Design (Part I: Preliminary Sizing of Airplanes). 


$$
\frac{W_{5}}{W_{4}}=\frac{1}{\exp \left(\frac{R}{\left(V_{T A S} / c j\right) \times(L / D)}\right)}
$$

Dalam buku Maido Saarlas (Aircraft Performance,2010) menuliskan bahwa dalam kondisi stalling speed berlaku persamaan:

Karena yang diketahui adalah $C_{\max } 2 \mathrm{D}$ maka perlu dihitung $\mathrm{C}_{\mathrm{Lmax}} 3 \mathrm{D}$ yang dirumuskan pada persamaan (3.8).

$C_{L \max }=0,9 \times C_{l \max } \times \cos \Lambda_{0,25 \text { chord }}$

Kecepatan stall dari suatu pesawat terbang dirumuskan pada persamaan (3.9).

$V_{S}=\sqrt{\frac{2 \times^{W_{5} / S}}{\rho \times C_{L \max }}}$

Setelah itu, bila memperhitungkan nilai load factor maka $\mathrm{V}_{\text {stall }}$ dirumuskan dengan:

$V_{\text {Sturn }}=V_{S} \times \sqrt{n}$

\section{Hasil dan Pembahasan}

Dalam proses rekonstruksi, dapat diperoleh animasi/video penerbangan terakhir dari pesawat dan juga flight path yang ditampilkan di aplikasi google earth. Dalam analisis, hasil rekonstruksi dalam bentuk animasi tidak mutlak diperlukan. Hal ini (animasi) diperlukan bila analis/investigator menginginkan visualisasi yang lengkap dari pesawat terbang, sedangkan bila informasi yang diperoleh dianggap sudah cukup dari flight path yang ada di google earth maka animasi tidak diperlukan lagi.

Dalam melakukan analisis, analis yang menggunakan animasi dapat melihat kondisi dan performa pesawat terbang melalui tampilan panel instrumen yang ada. Sedangkan bila menggunakan google earth, analis dapat melihat perubahan kondisi dan performa pesawat melalui beberapa parameter yang sudah dipilih untuk dianalisis dalam berkas ".csv" yang dikonversi ke ".kml" (misalkan time, heading, wind speed, horizontal speed, dan lain-lain).

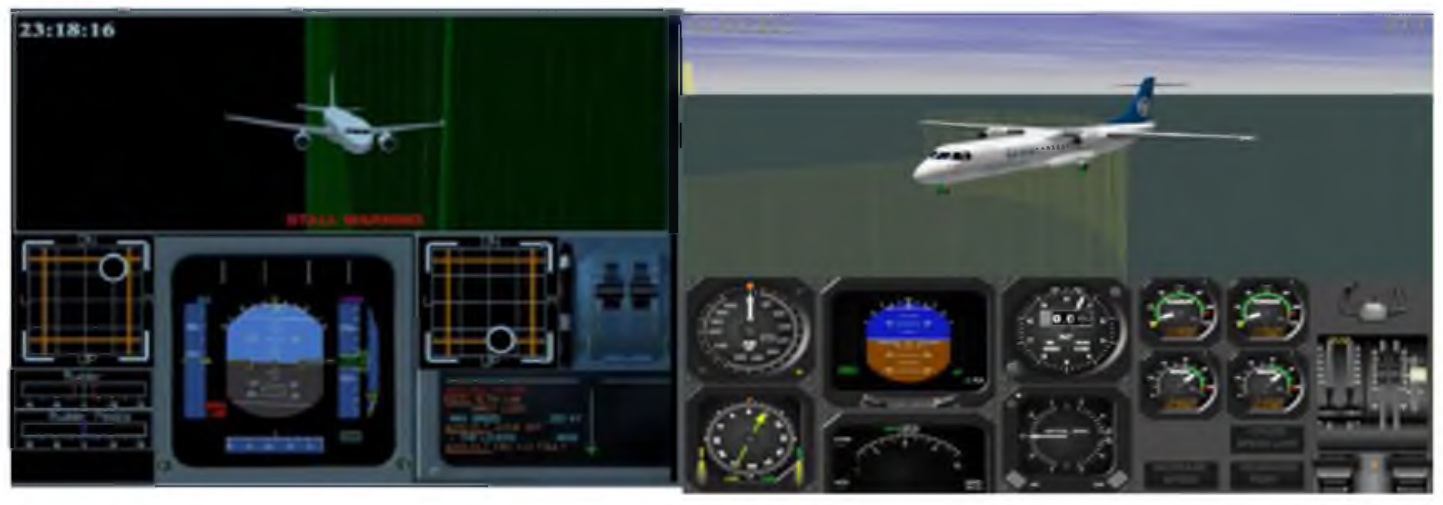

Gambar 3.1 Tampilan Panel Instrumen Saat Rekonstruksi 


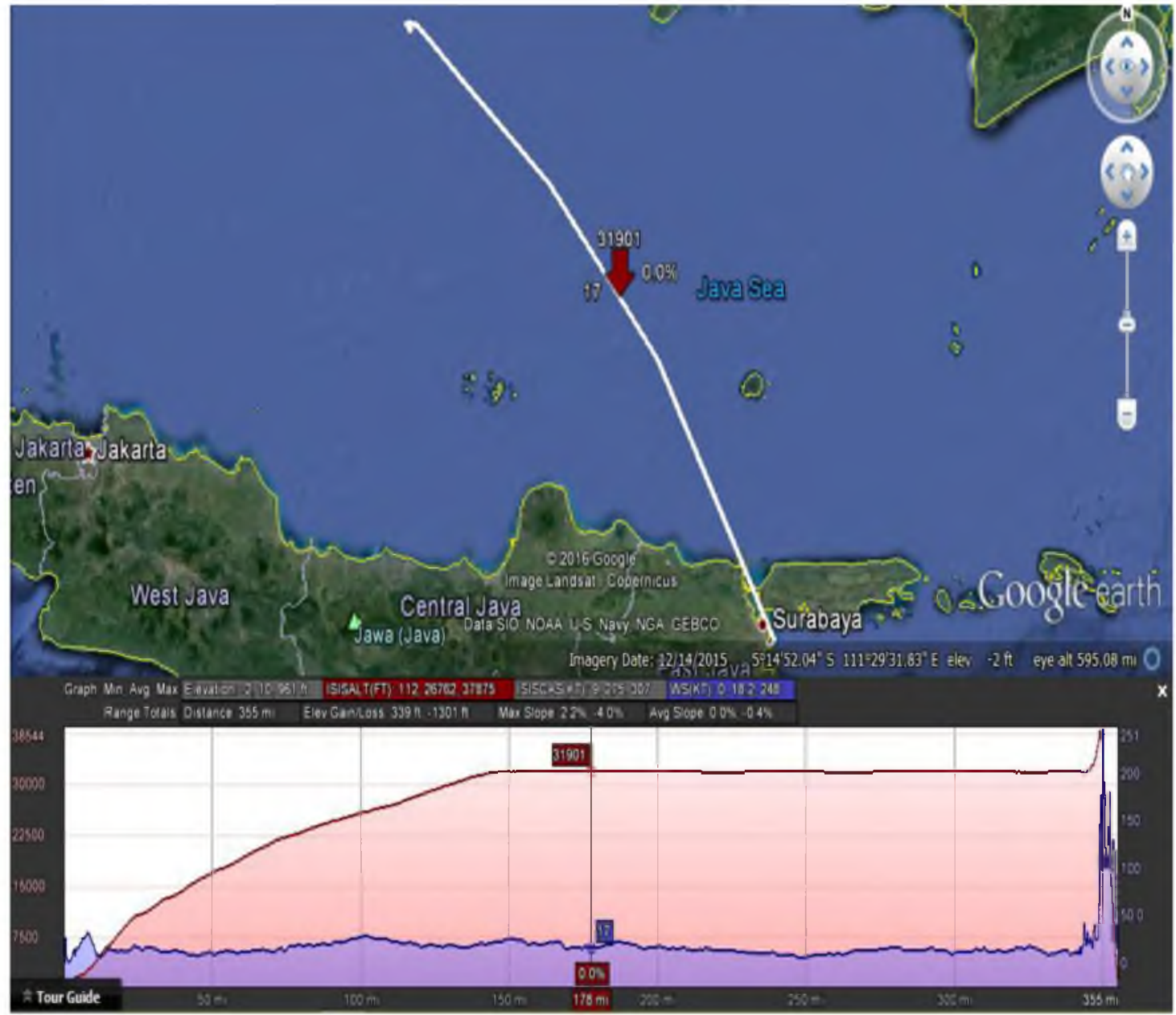

Gambar 3.2 Tampilan di Google Earth Saat Rekonstruksi

Untuk proses visualisasi, rekonstruksi dalam bentuk animasi lebih baik namun pembacaan data/data penerbangan yang ditampilkan tidak menunjukan angka yang spesifik. Sedangkan bila menggunakan google earth, data penerbangan/angka yang ditampikan lebih spesifik, sehingga cocok digunakan untuk proses analisis.

Dalam skripsi ini, google earth digunakan untuk melihat dan menganalisis kondisi terbang dari pesawat A320. Sedangkan untuk videonya hanya ditampilkan terbatas untuk kalangan tertentu karena berhubungan dengan keamanan dan privasi dari perusahaan penerbangan dan anggota keluarga yang mengalami kecelakaan (karena videonya berisi rekaman suara, dan hal ini dilarang oleh regulasi yang tertuang dalam ICAO Annex 13 untuk menampilkannya). Data yang dihasilkan/ditampilkan oleh Flightscape sama persis seperti data yang terekam oleh FDR. 


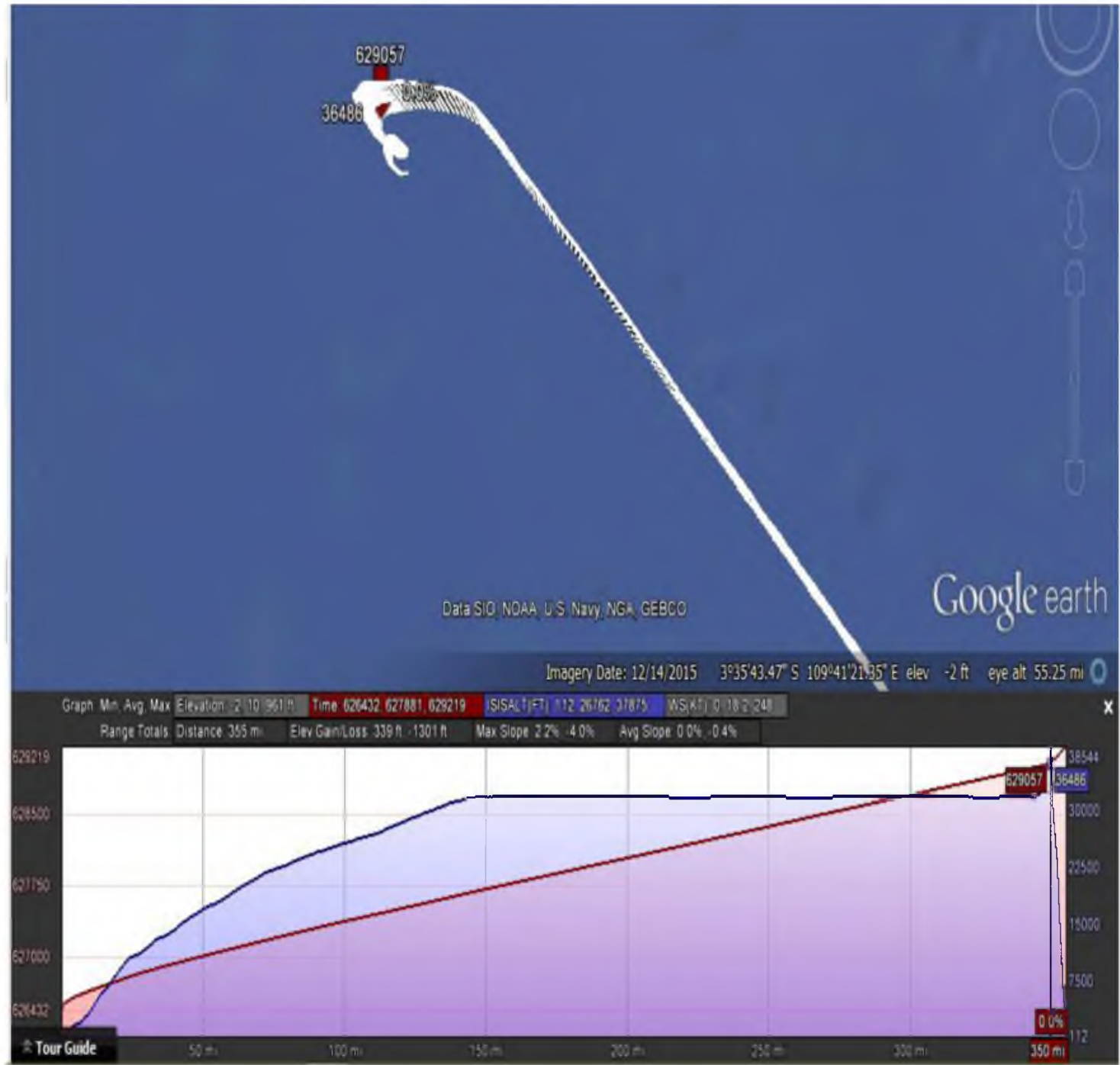

Gambar 3.3 Kondisi Pesawat yang Seperti Berbalik Arah

Dari FDR yang ditampilkan di google earth terlihat bahwa ketika pesawat terbang mengalami stall, pesawat berputar dengan perubahan derajat putar seperti berbalik arah ke tempat keberangkatan, atau karena bidang kendalinya tidak bekerja secara baik sehingga pesawat mengalami turning, ataupun juga ingin mencari bandara terdekat sebagai alternate landing. Data FDR terkait latituda dan longituda pesawat yang tersimpan di berkas ".csv" tidak menunjukan data yang sesuai, maka dari itu digunakanlah google earth yang menunjukannya lebih baik. Sedangkan untuk menampilkan altitude dan kecepatan dari pesawat maka digunakanlah data FDR yang tersimpan dalam berkas ".csv".

Berikut adalah perbandingan antara data FDR dengan hasil pendekatan secara analitik saat stall warning pertamakali terdengar dan pesawat terbang masuk dalam kondisi stall : 
Tabel 3.1 Perbandingan Data Pendekatan Analitik dengan Data FDR

\begin{tabular}{|c|c|c|}
\hline Parameter & Stall Warning Pertama & $\begin{array}{c}\text { Stall Condition 3 s } \\
\text { BeforeCrash }\end{array}$ \\
\hline Altitude & $31.396 \mathrm{ft}$ & $1.832 \mathrm{ft}$ \\
\hline$a$ & $7,7^{\circ}$ & $49,9^{\circ}$ \\
\hline $\mathrm{V}_{\mathrm{CAS}}$ & $272 \mathrm{kts}$ & $97 \mathrm{kts}$ \\
\hline $\mathrm{V}_{\mathrm{TAS}}$ & $246,137 \mathrm{kts}$ & $143,3193 \mathrm{kts}$ \\
\hline Wind Speed & $30 \mathrm{kts}$ & $55 \mathrm{kts}$ \\
\hline $\mathrm{C}_{\mathrm{Lmax}}$ & \multicolumn{2}{|c|}{1,3703} \\
\hline $\mathrm{M}$ & 0,4205 & 0,2182 \\
\hline $\mathrm{V}_{\text {stall }}$ & $127,6673 \mathrm{~m} / \mathrm{s}=$ & $76,8707 \mathrm{~m} / \mathrm{s}=$ \\
& $248,0069 \mathrm{kts}$ & $149,3292 \mathrm{kts}$ \\
\hline $\mathrm{V}_{\mathrm{Sturn}}$ & $179,1896 \mathrm{~m} / \mathrm{s}=$ & $77,6356 \mathrm{~m} / \mathrm{s}=$ \\
& $348,0942 \mathrm{kts}$ & $150,8151 \mathrm{kts}$ \\
\hline
\end{tabular}

Stall warning yang pertama terdengar karena $\alpha$ dan yang timbul sudah melebihi $\alpha_{\max }$. Selain itu pesawat sudah sulit dikendalikan yang berujung pada pesawat tetap kehilangan ketinggian karena pengaruh bidang kendali (rudder) yang mengalami gangguan ketika Pilot melakukan resetpada circuit breakers, karena proses reset hanya boleh dilakukan ketika di ground. Circuit breakers tadi tidak berfungsi mengalirkan listrik dengan baik karena menurut hasil investigasi yang dirilis oleh KNKT ditemukan adanya crack di sambungan circuit breakers. Bidang kendali yang sulit dikendalikan tadi mengakibatkan pesawat terbang miring, berbelok, bahkan melakukan turning sehingga mengakibatkan stall, yang mana sesuai dengan pernyataan Desmond Hutagaol "...stall dapat juga terjadi lebih dini bila pesawat sedang miring atau terbang berbelok,...".

Pada kondisi stall tiga detik sebelum crash $\alpha$ telah berada pada kondisi $49,9^{\circ}$ yang telah melampaui $\alpha$ maksimum yaitu $7,25^{\circ}$, dan juga diperparah lagi dengan kecepatan angin yang melebihi kecepatan angin maksimum yang mampu diterima oleh pesawat, dan arah angin/relative wind yang berasal dari atas pesawat sehingga engine kurang mendapat pasokan udara untuk pembakaran. Kurangnya pasokan udara berimbas pada kecepatan pesawat yang lebih kecil daripada kecepatan stall yang timbul. Hanya dalam waktu 3'36" dengan ekstrimnya pesawat kehilangan altitude karena bidang kendali yang sulit dikendalikan dan juga kecepatan stall yang begitu tinggi melebihi kecepatan yang dihasilkan untuk menjaga altitude pesawat sehingga pesawat terus bergerak ke bawah. Pergerakan pesawat ke bawah semakin cepat juga karena mendapat tekanan dari kecepatan angin (55 kts) yang telah melebihi kecepatan maksimum yang mampu diterima oleh pesawat.

Pada akhirnya, bila mengacu pada pernyataan Raymer (Aircraft Design: A Conceptual Approach, 1992) yang mengatakan bahwa "dalam aplikasi penerbangan sipil, kecepatan pesawat terbang paling sedikit harus tiga kali kecepatan stall $\left(\mathrm{V}_{\mathrm{TAS}}=\right.$ safety velocity $=3 \mathrm{x}$ $\mathrm{V}_{\text {stall }}$ ) agar pesawat tidak masuk dalam kondisi stall' maka pesawat yang dianalisis ini sudah masuk dalam keadaan unsafety velocity karena $\mathrm{V}_{\mathrm{TAS}}<\mathrm{V}_{\text {stall }}$. 


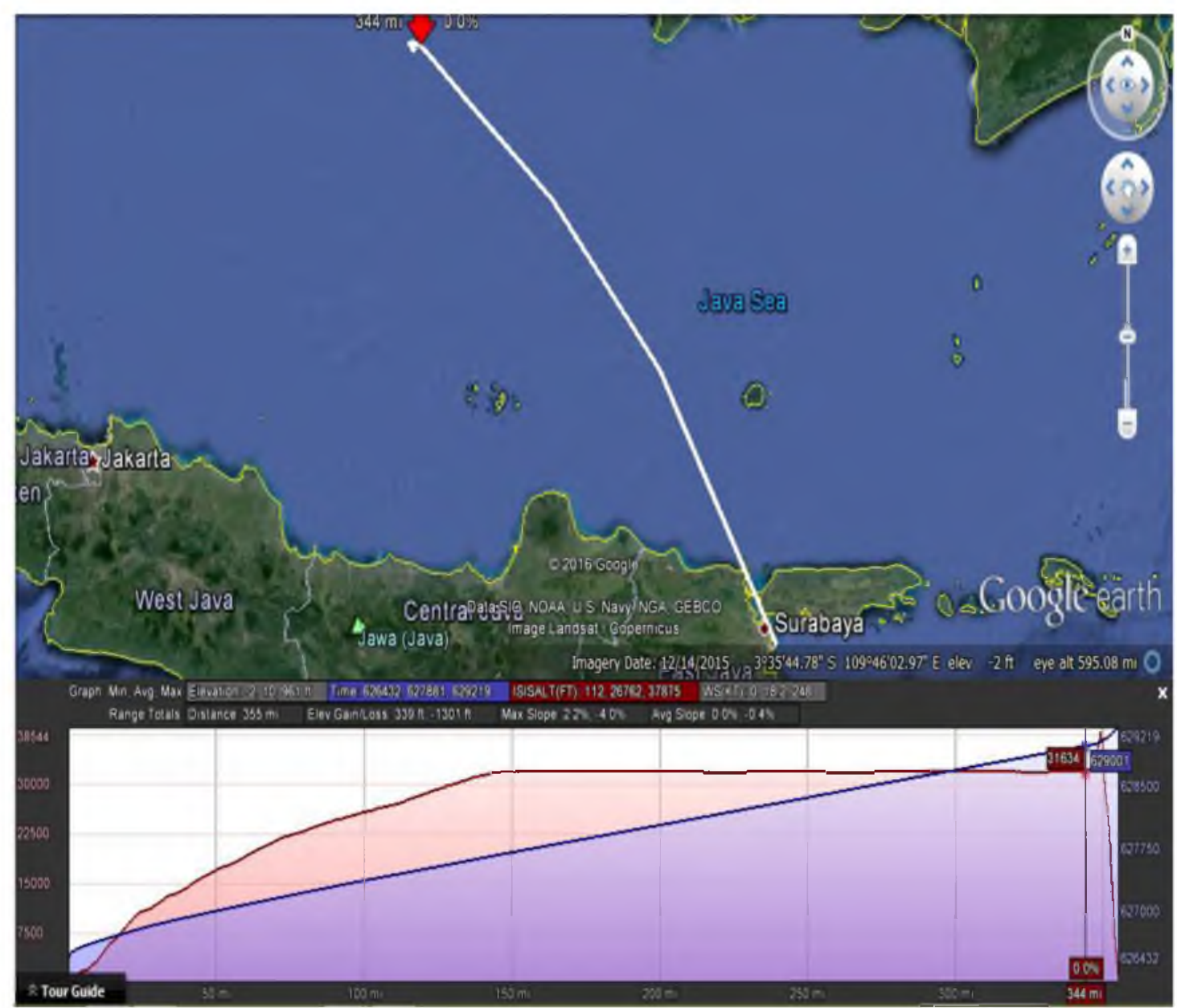

Gambar 3.4 Lokasi Stall Warning Pertamakali Berbunyi

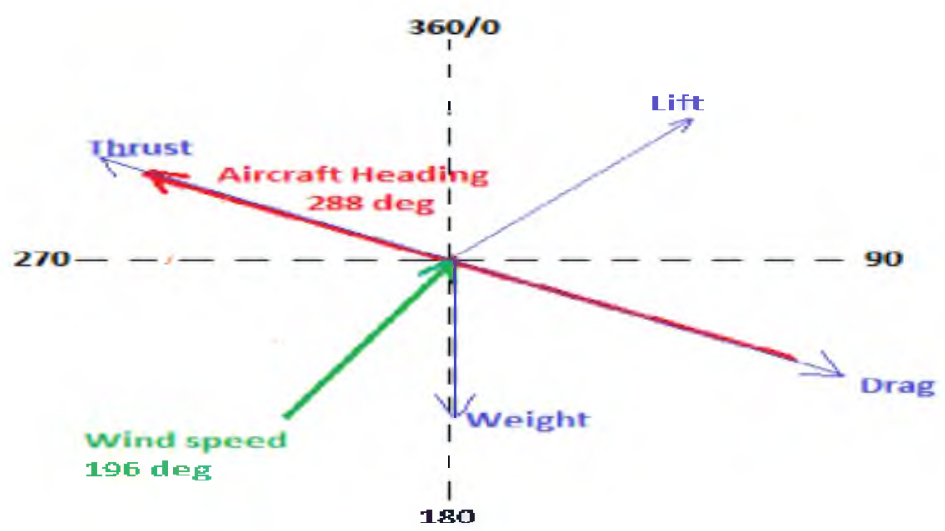

Gambar 3.5 Sumbu Arah Pesawat Saat Stall Warning Pertama 
Analisis Flight Data Recorder Kecelakaan (...)

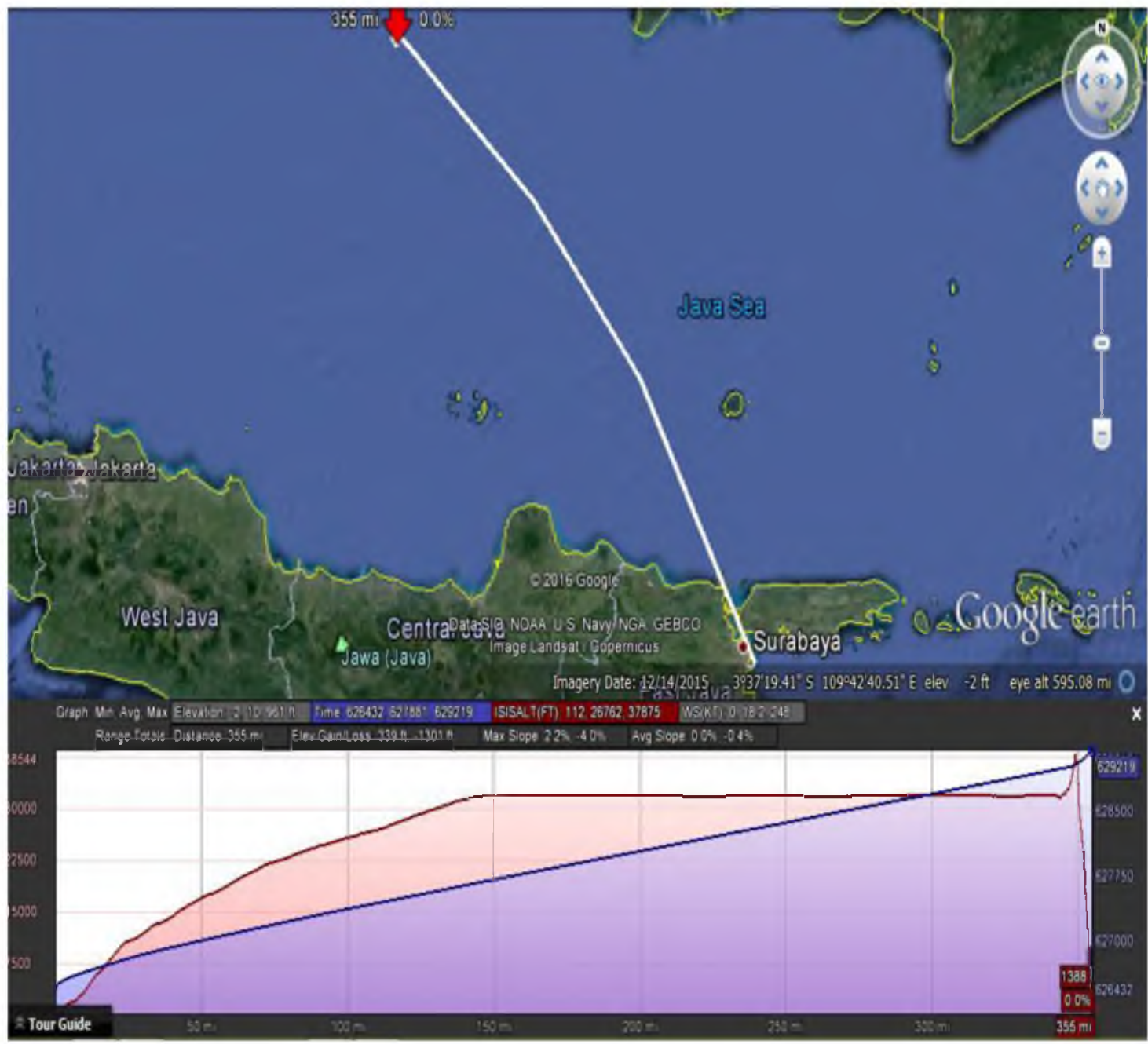

Gambar 3.6 Lokasi Tiga Detik Sebelum Crash

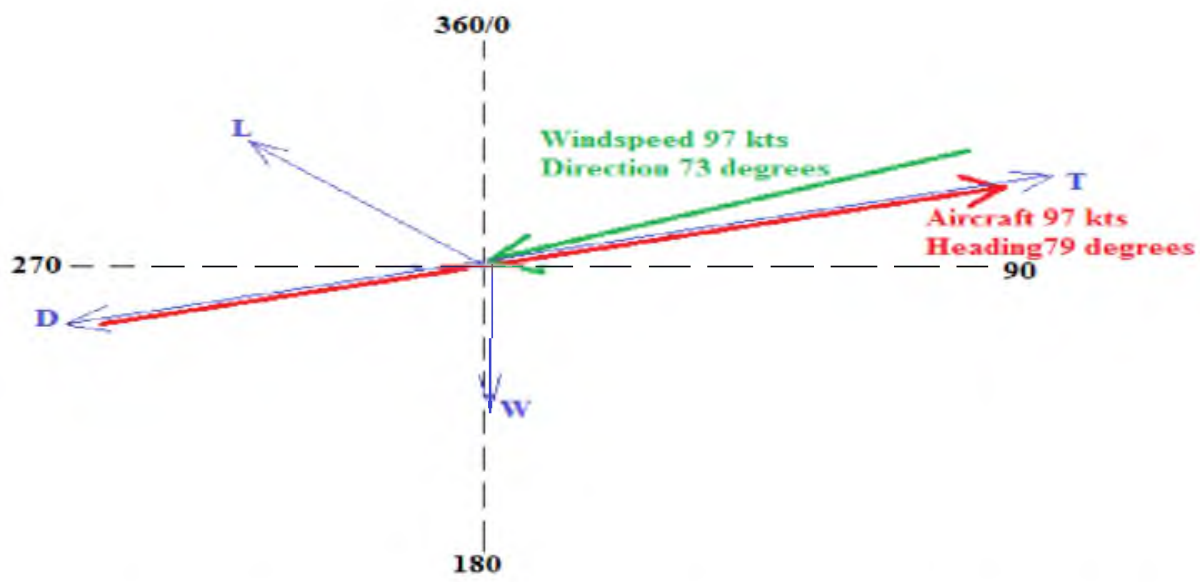

Gambar 3.7 Sumbu Arah Pesawat Saat 3 Detik Sebelum Crash 


\section{Kesimpulan}

Berdasarkan pembahasan maka dapat disimpulkan dalam penelitian ini bahwa nilai kecepatan stall yang dialami oleh pesawat terbang yang dianalisis :

\begin{tabular}{|c|c|c|}
\hline Kondisi & $\begin{array}{c}\text { Stall Warning } \\
\text { (knots) }\end{array}$ & $\begin{array}{c}\text { Stall Condition 3 s } \\
\text { BeforeCrash } \\
\text { (knots) }\end{array}$ \\
\hline $\mathrm{V}_{\mathrm{CAS}}$ (data FDR) & 272 & 97 \\
\hline $\mathrm{V}_{\mathrm{TAS}}$ (data FDR) & 246,137 & 143,3193 \\
\hline $\mathrm{V}_{\text {Wind }}$ (data FDR) & 30 & 55 \\
\hline Stall Speed Analytic & 348,0942 & 150,8151 \\
& & \\
\hline
\end{tabular}

\section{Daftar Pustaka}

Adiyasa, Purwa, 2015, Pemodelan Pesawat CN-235 dengan Software Simulasi X-Plane 10, Skripsi STTA.

Airbus, 2014, A-320 Airplane Flight Manual.

Anderson, John D., 2010, Aircraft Performance and Design, Tata McGraw Hill Education Private Limited, New Delhi, India.

Asyisyam, Akbar, 2008, Analisis Prestasi Terbang Boeing 747-400 Menggunakan Software X-Plane Pada Fasa Take-off dan Climb, Skripsi Institut Teknologi Bandung.

Cavcar, Mustafa, Stall Speed, Anadolu University, Turki.

Hutagaol, Desmond, Pengantar Penerbangan Perspektıf Profesional. Jakarta: Erlangga.

Komite Nasional Keselamatan Transportasi, 2015, Final Report KNKT 14.12.29.04 (PK$\mathrm{AXC}$ ).

Raymer, Daniel P., 1992, Aircraft Design: A Conceptual Approach. $2^{\text {nd }}$ edition, AIAA.Inc., Washington D.C, USA.

Roskam, Jan D., Lan, Chuan-Tau Edward, 1997. Airplane Aerodynamics and Performance.DARCorporation, Kansas, USA.

Roskam, Jan. D., 1985. Airplane Design (Part I: Preliminary Sizing of Airplanes), Roskam Aviation and Engineering Corporation, Kansas, USA.

Saarlas, Maido, 2007, Aricraft Performance, John Wiley \& Sons Inc., USA.

Sembiring, Javensius, 2007, Rancang Bangun Sistem Rekonstruksi Lintas Terbang Pesawat Udara dengan Perangkat Lunak X-Plane, Tesis Institut Teknologi Bandung. 